\title{
COVID-19: Concern and Education for Global Health for a Have-to Traveler
}

\author{
Ashok Chakraborty ${ }^{1 *}$, Smita Guha ${ }^{2}$ \\ ${ }^{1}$ School of Medicine, Yale University, New Haven, USA \\ ${ }^{2}$ St. John's University, New York, USA \\ Corresponding Author: Ashok Chakraborty, PhD, Professor, School of Medicine, Yale University, New Haven, USA. \\ Tel: +1-2036409433, Email: ashok.chakraborty@yale.edu
}

Received May 12, 2020; Accepted July 27, 2020; Online Published August 26, 2020

\begin{abstract}
COVID-19, a severe respiratory disease mediated by SARS-CoV-2 virus, is an extremely infectious. This virus was a recant outbreak from Wuhan City of China in late December 2019, but no remedy has been found yet. The coronavirus can spread mainly from person to person when they come in close contact with each other. Respiratory droplets from an infected person's infect any nearby people. Furthermore, asymptomatic person can also infect others. Data and information were searched from Web Science, Google Scholar, and PubMed databases, and the articles published before June 2020, using relevant keywords. WHO, CDC and other Govt. Agencies have published a protective measure for better prevention of the COVID-19 disease until vaccines or any other antivirals become available.

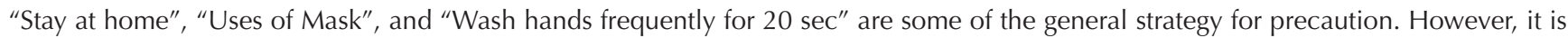
not possible for the "must travellers/traveler" and/or "front-line workers" to "stay at home". The concerns of the must-traveler and front-line workers to avoid any unwanted consequences that may arise from their traveling issues were discussed in this review.

Keywords: COVID-19, SARS-CoV-2, Pandemics, Travel, Quarantine
\end{abstract}

Citation: Chakraborty A, Guha S. COVID-19: concern and education for global health for a have-to traveler. Int J Travel Med Glob Health. 2021;9(1):4-9. doi:10.34172/ijtmgh.2021.02.

\section{Introduction}

A recent threat to human health is coronavirus disease 2019 (COVID-19), a deadly respiratory tract infection from a newly identified human SARS coronavirus, severe acute respiratory syndrome coronavirus 2 (SARS-CoV-2). ${ }^{1}$ This virus, as we know, originated in late December 2019 in Wuhan, China, and has now become a global pandemic. Previously, the 2002 SARS-CoV outbreak in China, which caused Severe Acute Respiratory Syndrome (SARS) had a mortality rate $>10 \%{ }^{2}$ A MERS (Middle East Respiratory Syndrome) outbreak occurred in Saudi Arabia in 2012 and had a mortality rate $>34 \%$. ${ }^{3}$ The mortality rate of the new COVID-19 pandemic is estimated at 3-4\%, much less than that of SARS or MERS, but higher than that of the seasonal flu (about 0.1\%). ${ }^{4}$ This statistic will only be true if a vaccine or antiviral remedy against COVID-19 is found; until then, no number can be correctly estimated for this disease.

Interestingly, SARS-CoV-2, like SARS-CoV and MERS$\mathrm{CoV}$, was first found in bats before spreading to humans ${ }^{5}$ and infecting the lower track of the human respiratory system. ${ }^{6,7}$ Coronaviruses are named for the crown-like spike structures on their surfaces that can be viewed under a microscope (corona means "crown"). ${ }^{8}$

The most important concern with this novel SARS-CoV-2 coronavirus is that it has tremendous infection abilities and can be fatal, especially among elderly people who have low immune strength and/or underlying conditions, such as heart issues, diabetes, or cancer. ${ }^{9}$ Furthermore, no treatment or cure for this disease has been developed to date. Therefore, we have to rely only on self-protection as guided by the CDC, WHO, and other governmental agencies and supported by scientists and healthcare workers.

The general guidelines, as directed by the CDC, are: ${ }^{10}$

- Avoid crowds; maintain social distancing (at least $6 \mathrm{ft}$ of physical distance from others);

- Wash hands frequently with soap for 20-25 seconds, especially after returning from a public place or touching any surfaces; practice etiquette during coughing or sneezing and follow such events by washing hands again;

- Use hand sanitizer often;

- Wear a cloth facemask in public;

- Follow lock-down rules set up by government officials

Copyright $(\mathcal{O} 2021$ The Author(s). This is an open-access article distributed under the terms of the Creative Commons Attribution License (http:// creativecommons.org/licenses/by/4.0), which permits unrestricted use, distribution, and reproduction in any medium, provided the original work is properly cited. 
(Frontline workers are excused); and

- Follow travel-ban rules to lower the infection rate.

The guidelines have so far proven to flatten the exponentially growing curve of the number of infected people and mortality rate. However, many questions and other issues on social, economic, and many other aspects of human life still remain as big unanswered concerns.

Herein, the discussion is restricted to issues related to travel which, in some cases, is unavoidable. The conflict between the guidelines and the concerns of the have-to travelers, i.e. those who must travel to give services to needy people, like doctors, nurses, healthcare workers, administrators, scientists working in labs to find remedies, support givers to friends and families, and many more are still unanswered.

Some general information about COVID-19 and its precautionary guidelines are portrayed in a question-andanswer format in Table 1, and the detailed concerns of have-to travelers are shown in Tables 2 and 3.

Table 1. General Information About COVID-19

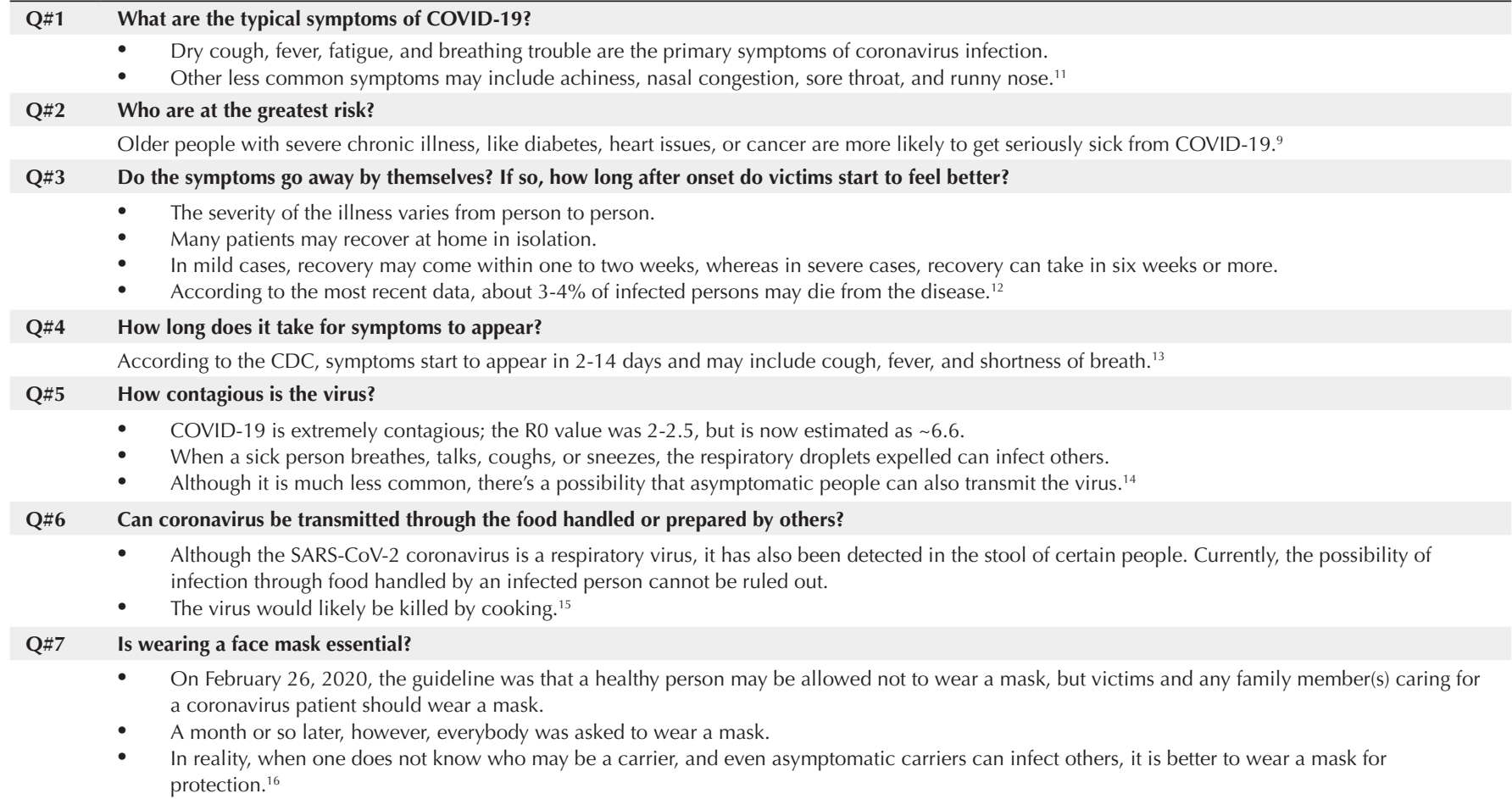

Q\#8 What can one do to keep one's immune system strong?

The body's primary defense is the immune system. Some ways to keep the immune system strong and healthy include:

- $\quad$ Not smoking

- Consuming a diet rich in vegetables, whole grains, and fruits.

- Taking multivitamins regularly

- Exercising regularly

- Maintaining a healthy weight through diet and physical activity.

- Controlling stress level, both physical and mental.

- Controlling blood pressure.

- Consuming alcohol sensibly and in moderation.

- $\quad$ Getting good and enough sleep.

- $\quad$ Avoiding infection by practicing good sanitation. ${ }^{17}$

Q\#9 If one is infected with coronavirus, what are the chances of survival and recovery?

- The vast majority of people with coronavirus recover and survive.

- The death rate, so far is about 3-4\%, according to the National Institute of Allergy and Infectious Diseases. ${ }^{18}$

Q\#10 How long does it take to recover?

- $\quad$ Recovery usually takes nearly six weeks..$^{19}$

Q\#11 When can one discontinue self-isolation or self-quarantine?

- It depends on the case.

- The $\mathrm{CDC}$ recommends at least 14 days of self-isolation for those who are infected.

- However, in special cases, the decision should be made based on the risk of infecting others and after discussion with one's doctor and state and local health departments. ${ }^{20}$

Q\#12 Can a person who has had coronavirus be re-infected?

- $\quad$ The answer is not yet known. Most people would likely develop some short-term immunity to the specific coronavirus that causes COVID-19.

- However, mutations of the virus strain can often make one re-susceptible. ${ }^{21}$

Q\#13 After recovery from the disease, when is it safe to go out in public again?

Research has shown that the viral genetic material remains in the patient's body even several weeks after recovery from COVID-19. Therefore, it is safest to assume that the person still may be contagious ever after his recovery. ${ }^{22}$ 
Table 2. COVID-19: Concerns of Travelers

Q\#1 Below are the common guidelines from the CDC for protection from corona infections.

- Limit in-person contact with people who are showing symptoms of COVID-19 or any respiratory infection.

- Maintain good hygiene to prevent the spread of pathogens.

- Wash hands thoroughly with soap and water for at least 20 seconds.

- $\quad$ Keep a distance of at least 6 feet from anyone who is coughing or sneezing.

- Disinfect often objects like phones, computers, and door knobs. ${ }^{10}$

Q\#2 What are the guidelines for have-to travelers?

- Try to stay at home as much as possible.

- Work from home, if possible.

- $\quad$ Follow social distancing guidelines.

- Wash hands frequently and practice good etiquette by coughing or sneezing into your elbow.

- $\quad$ Switch in-person meetings to teleconferences and avoid handshakes. ${ }^{23}$

Q\#3 How about using public transportation?

- Public transit could increase one's risk of exposure to coronavirus.

- Alternative means of transportation would be better. ${ }^{24}$

Q\#4 Is it safe to travel by airplane?

- $\quad$ Stay updated on travel advisories from regulatory agencies.

- $\quad$ Anyone who has a fever and cough should not fly.

- According to the CDC, because the mechanism of air circulation and filtration in planes is a high-tech device, most viruses do not spread easily on airplanes..$^{23}$

Q\#5 What about traveling domestically?

- It is better to check out the website of the local official tourism service before traveling, because state-mandate travel restrictions vary widely.

- In most states, 14 days of quarantine are required before entering. ${ }^{23}$

Q\#6 Can I take a road trip?

- Yes; however, it is required there too, to quarantine for 14-days at most check points..$^{23}$

Q\#7 Precautions when you rent a car.

- Compared to public transportation, a personal or rented car presents a lower risk of getting or spreading COVID-19, since one is exposed to fewer people.

- $\quad$ COVID-19 transmission is mostly caused by person-to-person contact.

- To reduce the risk, even in a rental car, one should wipe down highly touched areas and increase ventilation..$^{23}$

Q\#8 Rental Hotels

- Most hotels are closed temporarily.

- In Vermont, even with a negative test for Covid-19, quarantining for seven days is still required. ${ }^{23}$

$\mathrm{Q} \# 9 \quad$ Is flying in a private plane safer than flying commercial from a health point of view?

- Traveling in a private plane is much safer, but not all the time.

- $\quad$ One may not know who occupied the seat previously and whether or not it was efficiently decontaminated..$^{23}$

Q\#10 How about cruises altogether?

- $\quad$ The CDC and the U.S. State Department issued heightened travel warnings, advising travelers to defer all cruise ship travel worldwide. ${ }^{23}$

Q\#11 What if you were on a cruise in the last 14 days?

- Stay home for 14 days after returning.

- Maintain social distancing, and watch your health condition. ${ }^{25}$

Q\#12 Is it safe to visit family or friends?

- Avoid traveling during this pandemic situation as travel increases one's chances of contracting and spreading COVID-19.

- Before traveling, know the most recent situation of COVID-19 in your area and the places you wish to travel.

- The situation will be more dangerous if you or your loved ones are at higher risk for severe illness, and therefore need to take extra precautions. ${ }^{26}$

Q\#13 Is it safe to go camping?

- $\quad$ Camping is not at all advisable, especially when the community is experiencing a pandemic spread of COVID-19.

- Close contact with others or sharing public facilities (like restrooms or picnic areas) at campsites may be unsafe.

- Many local, state, and national public parks have been temporarily closed due to COVID-19. ${ }^{27}$ 
Table 3. COVID-19: Precautions Before Traveling ${ }^{28}$

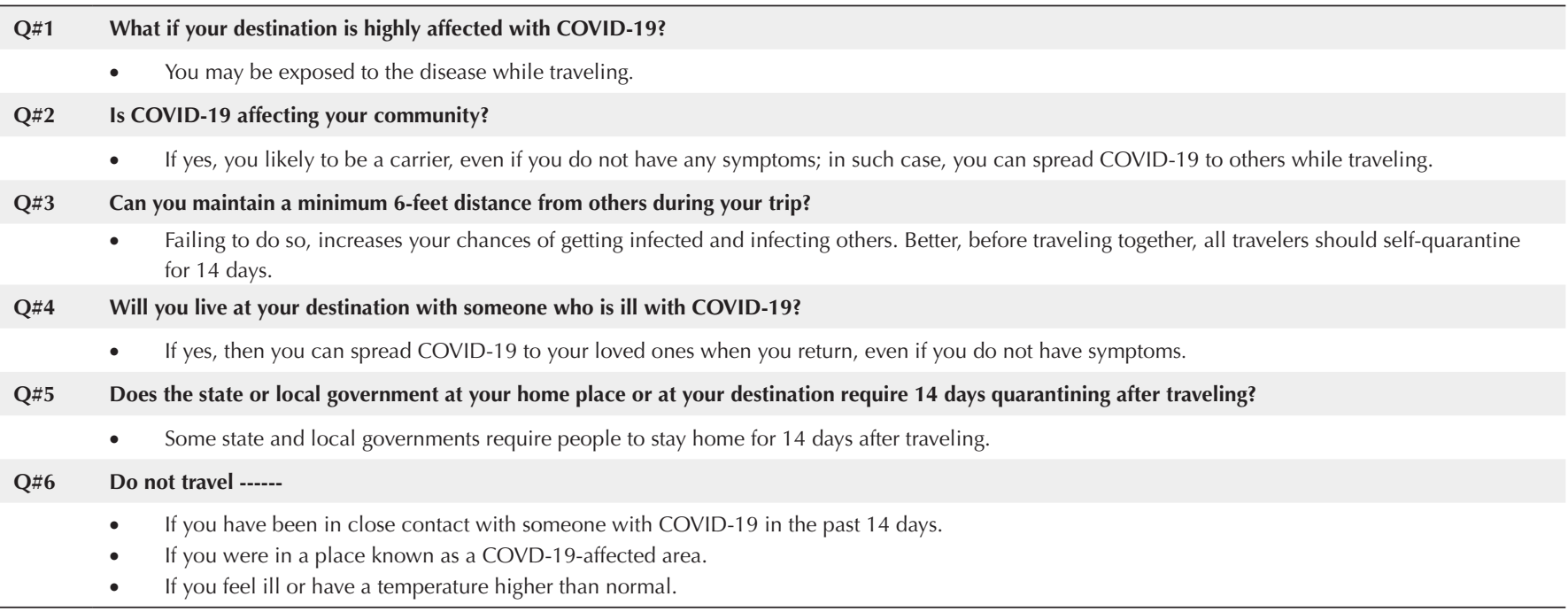

\section{Some Considerations Before Traveling to Protect Oneself and Others}

Considerations of Travel Types

Chances of getting infection from COVID-19 can be increased from traveling. It is not clear which types of travel are safer than others. The most commonly used travel types are air, bus or train, car, and recreational vehicle (RV) travel.

\section{Air Travel}

Long times spent during security check-in and in airport terminals place travelers in the close vicinity of others. The presence of efficient filtered air circulation systems on airplanes, however, generally prevent most viruses and other germs from spreading on flights.

\section{Bus or Train Travel}

Traveling on trains or buses for any distance may not permit one to maintain the minimum social distance from others; therefore, chances of infection may increase.

Car Travel

While better than the above-named modes of travel, stops for gas, food, or rest areas can while traveling by car may bring one into close contact with other people and frequently touched surfaces.

\section{RV Travel}

While traveling in an $\mathrm{RV}$, it is true that one does not have to stop often for food or rest areas, but RV travelers need to stay at RV parks and get supplies from other public places. These stops may put one in close contact with others.

In brief, maintaining social distancing is difficult in public places like airports, train stations, bus stations, and rest areas, spots where it is easiest to be exposed to the virus.

\section{Personal Medicines/Disinfectants}

One should carry a large enough supply of personal medicines and disinfectants to last for the entire trip:

- Pack enough alcohol-based hand sanitizer;
- Take along cloth face masks;

- Carry prepared food and water;

- Pack non-perishable food;

- Follow the CDC's guidelines on how to clean and disinfect surfaces.

Know State and Local Travel Restrictions

It is important to obtain the most recent information about the status of COVID-19 infection at one's destination before traveling from the state or local health department; any restrictions should be followed.

\section{Discussion}

COVID-19 is a respiratory disease caused by the SARS$\mathrm{CoV}-2$ human coronavirus. There are many sub-groupings of coronaviruses, known as $\alpha, \beta, \gamma$, and $\delta$.SARS-CoV-2 fallsin the $\beta$ subgroup, like SARS and MERS. They are called coronaviruses due to the crown-like (corona means crown) spikes on their surfaces as seen in electron-microscopic images. ${ }^{1}$ All viruses from the $\beta$ subgroup cause a severe respiratory illness with higher rates of morbidity and mortality, whereas viruses from other subgroups (HCoV-NL-63, HCoV-229E, HCoV-OC43, and all $\alpha$-subgroup viruses) usually cause mild-to-moderate upper-respiratory tract illnesses, like the common cold.

An attempt was made to present in Tables 2 and 3 the various guidelines aimed mainly at travelers who are concerned about the disease progress and their obligation to follow general guidelines but must travel because of their responsibilities.

In order to protect public health during the COVID-19 pandemic, it is advisable that people should social distance as much as possible. It is true that millions of people must continue their work outside the home to make this collective response possible. Therefore, the country should have a moral responsibility to protect these essential workers' health by providing free life and health insurance and financial security for healthcare workers' families. Such benefits may bring these workers at least some peace of mind during this period of mental and physical stress.

The need to travel during the pandemic must be re- 


\section{Review Highlights}

\section{What Is Already Known?}

Different agencies have published a protective measure for better prevention of the COVID-19 disease until vaccines or any other antivirals become available.

\section{What This Study Adds?}

This manuscript adds some new information especially for the 'must travelers' and/or "front-line workers". The protective measurement they should consider to avoid any unwanted consequences that may arise from their traveling situations, were discussed.

examined critically and scientifically in order to answer the questions of when is travel restriction justified and to what extent? Most importantly, all countries should align for the global health interest as well as their own national interests in decision-making on challenging issues like travel health.

To understand how quarantining and traveling affect the spread of COVID-19, a meta-analysis was conducted by Chinazzi et al. ${ }^{29}$ The researchers showed that early detection of COVID-19 followed by hand washing, self-isolation, or quarantining are likely to be more effective than travel restriction in fighting against this pandemic disease.

\section{Conclusion}

COVID-19 is a pandemic disease, extremely contagious, and can be fatal. To date, no remedy or effective treatment for it has been developed. The only way to bypass infection is to take precautions as recommended by the CDC, WHO, and government officials. People must be logical and smart and take precautions to prevent the disease from flourishing further. Staying at home, using a mask, washing hands frequently for 20 seconds, and critically and scientifically reexamining the need to travel during this pandemic time are some general precautions.

\section{Authors' Contributions}

All the authors contributed equally to prepare this article, read and approved the final manuscript.

\section{Conflict of Interest Disclosures}

Both the authors declare no conflict of interests.

\section{Ethical Approval}

Not required.

\section{Funding/Support}

None.

\section{Acknowledgements}

We acknowledge all our colleagues for their help during the preparation of the manuscript by providing all the relevant information. We are also thankful to the Departmental Secretary (St. John's Univ.) for editing the manuscript.

\section{References}

1. Li H, Liu SM, Yu XH, Tang SL, Tang CK. Coronavirus disease 2019 (COVID-19): current status and future perspectives. Int J Antimicrob Agents. 2020;55(5):105951. doi:10.1016/j. ijantimicag.2020.105951.

2. Holmes EC, Rambaut A. Viral evolution and the emergence of SARS coronavirus. Philos Trans R Soc Lond B Biol Sci. 2004;359(1447):1059-1065. doi:10.1098/rstb.2004.1478.

3. Zaki AM, van Boheemen S, Bestebroer TM, Osterhaus AD, Fouchier RA. Isolation of a novel coronavirus from a man with pneumonia in Saudi Arabia. N Engl J Med. 2012;367(19):18141820. doi:10.1056/NEJMoa1211721.

4. Our World in Data. Statistics and Research: Mortality risk of COVID-19. https://ourworldindata.org/mortality-riskcovid? country $=\sim$ USA.

5. Hu B, Ge X, Wang LF, Shi Z. Bat origin of human coronaviruses. Virol J. 2015;12:221. doi:10.1186/s12985-015-0422-1.

6. Gu J, Korteweg C. Pathology and pathogenesis of severe acute respiratory syndrome. Am J Pathol. 2007;170(4):1136-1147. doi:10.2353/ajpath.2007.061088.

7. Cui J, Li F, Shi ZL. Origin and evolution of pathogenic coronaviruses. Nat Rev Microbiol. 2019;17(3):181-192. doi:10.1038/s41579018-0118-9.

8. Goldsmith CS, Tatti KM, Ksiazek TG, et al. Ultrastructural characterization of SARS coronavirus. Emerg Infect Dis. 2004;10(2):320-326. doi:10.3201/eid1002.030913.

9. Centers for Disease Control and Prevention (CDC). Coronavirus Disease 2019 (COVID-19): People Who Are at Increased Risk for Severe Illness. CDC; 2020. https://www.cdc.gov/coronavirus/2019ncov/need-extra-precautions/people-at-higher-risk.html.

10. Centers for Disease Control and Prevention (CDC). Public Health Guidance for Community-Related Exposure. CDC; 2020. https://www.cdc.gov/coronavirus/2019-ncov/php/public-healthrecommendations.html.

11. Centers for Disease Control and Prevention (CDC). Coronavirus Disease 2019 (COVID-19): Symptoms of Coronavirus Disease (COVID-19). CDC; 2020. https://www.cdc.gov/coronavirus/2019ncov/symptoms-testing/symptoms.html.

12. Healthcare in Europe. COVID-19 Symptoms Disappear - While the Virus Itself Remains. American Thoracic Society; 2020. https://healthcare-in-europe.com/en/news/covid-19-symptomsdisappear-while-the-virus-itself-remains.html.

13. Healthline. How Long is the Incubation Period for the Coronavirus? 2020. https://www.healthline.com/health/coronavirus-incubationperiod.

14. Edwards E. How Contagious is the Coronavirus. NBC; 2020. https://www.nbcnews.com/health/health-news/how-contagiouscoronavirus-n1175071.

15. Centers for Disease Control and Prevention (CDC). Food Safety and Coronavirus Disease 2019 (COVID-19). CDC; 2020. https:// www.health.harvard.edu/diseases-and-conditions/coronavirusresource-center.

16. Gray R. Why We Should All Be Wearing Face Masks. 1st ed. BBC Future; 2020. https://www.bbc.com/future/article/20200504coronavirus-what-is-the-best-kind-of-face-mask.

17. Harvard Medical School. Harvard Health Publishing. April 6, 2020 How to Boost your Immunity. https://www.health.harvard.edu/ staying-healthy/how-to-boost-your-immune-system. Published September 2014.

18. Groth L. What to Know About the Survival Rate of CoronavirusAnd How Many People Have Died From the Illness. Explore Health- Infectious Disease. April 9, 2020. https://www.health. com/condition/infectious-diseases/coronavirus-survival-rate.

19. WebMD: Coronavirus Recovery. WebMD Medical Reference Reviewed by Michael W. Smith, MD on April 09, 2020. https:// 
www.webmd.com/lung/covid-recovery-overview\#1.

20. CDC: Coronavirus disease (COVID-19) ; July 3, 2020. Quarantine If You Might Be Sick. https://www.cdc.gov/coronavirus/2019ncov/if-you-aresick/quarantine.html?

21. Norton A, Healthday Reporter. Can Survivors Get Reinfected with Coronavirus? Medical Express; 2020. https://medicalxpress.com/ news/2020-05-survivors-reinfectedcoronavirus.html.

22. Centers for Disease Control and Prevention (CDC). Coronavirus Disease 2019 (COVID-19). When You Can be Around Others After You Had or Likely Had COVID-19. CDC; 2020. https://www.cdc. gov/coronavirus/2019-ncov/if-you-are-sick/end-home-isolation. $\mathrm{html}$.

23. CDC: June 28, 2020. Considerations for Travelers-Coronavirus in the US, https://www.cdc.gov/coronavirus/2019-ncov/travelers/ travel-in-the-us.html.

24. UCLA Health. Coronavirus Pandemic: How to Use Public Transportation Safely. 2020. https://connect.uclahealth. org/2020/06/09/coronavirus-pandemic-how-to-use-publictransportation-safely/.
25. Centers for Disease Control and Prevention (CDC). CDC's Role in Helping Cruise Ship Travelers During the COVID-19 Pandemic. CDC; 2020. https://www.cdc.gov/coronavirus/2019-ncov/ travelers/cruise-ship/what-cdc-is-doing.html.

26. Bowden B. Is it Safe to Visit Family and Friends? As COVID-19 Pandemic Stretches on, Experts Weigh in. Wisconsin Public Radio; 2020. https://www.wpr.org/it-safe-visit-family-and-friends.

27. 27 Centers for Disease Control and Prevention (CDC). Is it Safe to Travel to Campgrounds or Go Camping? CDC; 2020. https://faq. coronavirus.gov/travel/is-it-safe-to-travel-to-campgrounds-or-gocamping/. Last updated April 30, 2020.

28. Centers for Disease Control and Prevention (CDC). Travel. CDC; 2020. https://www.cdc.gov/coronavirus/2019-ncov/travelers. Updated July 2, 2020.

29. Chinazzi M, Davis JT, Ajelli M, et al. The effect of travel restrictions on the spread of the 2019 novel coronavirus (COVID-19) outbreak. Science. 2020;368(6489):395-400. doi:10.1126/ science.aba9757. 